\title{
Note on the Translation and Transliteration of Terms
}

The spellings of authors' and artists' names follow their own stated preferences and/or common public usage (e.g., Yevgenia v. Evgenia). The names of places in Ukraine follow standardized modern Ukrainian, unless the reference is to a different usage in the original body of work being cited (e.g., Dnipro v. Dnipropetrovsk; Kyiv v. Kiev). I have chosen to refer to the events that took place over winter 2013-14 on Kyiv's central square, or Maidan, as the Maidan Revolution of Dignity, which reflects how these events are addressed by Ukrainians themselves and by state officials. The term "Maidan Revolution" appears in my text as shorthand for this particular moment, although there have been other mass gatherings on the same site at other times in history. The convention in Cyrillic of only capitalizing the initial word of a title appears only when this is the case in the original source. All transliteration follows the Library of Congress system.

\section{Note on the Archiving of Materials for Future Research}

Many of the primary published and unpublished texts, images, and other materials from Ukraine collected through the course of writing this book are not widely available. A fond has been opened in the author's name at the Joseph A. Labadie Collection at the University of Michigan where these materials are deposited. The Labadie is located at the Special Collections Research Center in Hatcher Library and is one of the largest collections documenting the history of social protest movements and revolution from the nineteenth century to the present. Sources for this book will be maintained at the Labadie, and the collection of materials pertaining to protest in Ukraine will be ongoing. 



\section{SUPERFLUOUS WOMEN}

Art, Feminism, and Revolution in

Twenty-First-Century Ukraine 
